\title{
The doctrine of the intelligent design from the point of view of the cognitive science of religion
}

\section{WOJCIECH P. GRYGIEL}

Department of Philosophy, The Pontifical University of John Paul II, Kraków

Copernicus Center for the Interdisciplinary Studies, Kraków

wojciech.grygiel@upjp2.edu.pl

ORCID: 0000-0003-2599-0410

\begin{abstract}
The doctrine of the Intelligent Design offers an intuitive explanation of why the ordering in the Universe is authored by an intentional agency. Due to its appeal to common-sense perception, this doctrine is endorsed even by scientifically literate circles despite of its obvious contradiction with the discoveries of science. In this article, an attempt to apply the tools of the cognitive science of religion to the appraisal of the methodological and epistemic status of the ID doctrine is presented. It is concluded that the ID doctrine may serve as means of the real-time metaphorical reassurance of the creative power of God while it cannot give grounds to any literal inferences on the nature of the Divine action.
\end{abstract}

Keywords: intelligent design; ordering; en tropy; mental states; probability.

\section{Introduction}

The belief in the ordered character of the Universe has been present in the human thought since the times of antiquity. The contemporary doctrine of the Intelligent Design (further denoted as ID) grew in the 1980's out of the 
creation science which aimed at providing scientific support for the literal account of creation as portrayed in the Book of Genesis (e.g. Keane 1999). In most general terms, the ID stipulates that the high level complexity and the ordering of the living organisms in the Universe as well as their adaptation to the demands of the environment imply that they were purposefully brought forth by an intelligent designer and not by the workings of the laws of nature. Although the inconclusiveness of these arguments is nowadays commonly accepted (e.g. Ayala 2009, 128-149), the efforts to justify the scientific character of the ID still receive considerable interests as they appeal to simple intuitions rather than sophisticated scientific arguments (e.g. Chaberek 2004; Giertych 2016; Jodkowski 2007).

The goal of the presented article is to subject the doctrine of the Intelligent Design (further denoted as ID) to the scrutiny of the tools of a novel division of cognitive science named the cognitive science of religion from both methodological and epistemic point of view. In particular, this scrutiny will allow for the assessment of the influence of the development of science on the validity ID's inferential power. So far it has been established with the methods of the cognitive science of religion that the argumentation in favor of the ID follows upon the content specific human cognition acquired in the course of specific evolutionary scenarios that have programmed the human mind to interpret the patterns of ordering in the Universe as resulting from the action of intentional agents (Barrett 2011). To put things bluntly, we are in-born "intelligent designers" whether we like it or not. It is not surprising that the belief in the ID turns out to be the most natural and immediate response to the experience of the ordering of the Universe. Moreover, it explains why the belief is so widespread in the common sense perception and why it takes time as well as scientific maturity to leave the pre-scientific intuitions behind.

The pursuit of the article's goal will proceed in the following steps. Firstly, the conceptual content of the ID doctrine will be surveyed to establish its fundamental claims. This step will hinge upon the precise distinction between ordering and design and the mechanisms of the spontaneous emergence of ordered structures in the Universe. Secondly, the cognitive mechanisms responsible for the preference of the human mind in placing 
the intentional agency as responsible for the effects of ordering will be presented. Thirdly, based on some preliminary considerations by Grygiel (2017), the impact of the development of science on the activation of these mechanisms will be assessed. And fourthly, it will be claimed that although the ID doctrine cannot serve as means to draw any specific conclusions on how ordering emerges in the Universe, it constitutes a suitable metaphor to support of the belief in God as the Creator of the Universe.

\section{The Intelligent Design and Its Conceptual Content}

Before the unpacking of the conceptual content of the ID doctrine is accomplished, it is worthwhile to carry out a simple semantic analysis of the concepts of order and design. In regards to order, its basic meaning derives from logic of relations to articulate the idea of precedence. No mention of the authorship of this order is ever made. The etymology of the term design, however, clearly refers to the activity of specifying or to singling out from among the many. Moreover, design is often used alternately with project. This yields meaning complementary to design, namely, that of throwing forward whereby a certain idea is metaphorically visualized as being thrown upon a chaotic substratum. Consequently, two semantic components of design must be taken into account: purpose and perfection. In regards to purpose, design implies the activity of a designer, namely, a conscious agent who, driven by a specific goal, makes a deliberate choice from a large number of options available. By acting with purpose the designer does not arbitrarily select any option available like in a lottery but elicits a considerable effort to arrive at a unique arrangement that fits his/her rational plan. Once this plan is placed in the framework of participation in the world of the Platonic eternal forms, it acquires the attribute of perfection.

This simple semantic analysis can be given a more precise meaning with the use of the mathematical concept of probability. The standard definition of probability understood as the ratio of the number of willed choices to the entire number of options from among which these choices can be made indicates that there might be an connection between events of low 
probability and the activity of an intentional agency. It seems intuitively fitting that the more unique the character of the choice, that is the lower its probability due to the precision of its selection, the need to postulate the designer's intervention appears to be more obvious. According to Aristotle, events of low probability qualify as accidental: "The accidental, then, is what occurs, but not always nor of necessity, nor for the most part. Now we have said what the accidental is, and it is obvious why there is no science of such a thing; for all science is of that which is always or for the most part, but the accidental is in neither of these classes" (Aristotle 1941, 862). This assertion brings in a new element into play, namely, that of qualifying chance events as intractable by the scientific method. Consequently, there arises a clear-cut intuitive dichotomy in the explanation of the occurrence of events in nature: high-probability predictable events occur as workings of the regularities built into nature while the low-probability chance events call for an intervention of an intentional agency.

With the conceptual tools thus specified it is now possible to tackle the conceptual content of the ID doctrine. It gained its greatest momentum in the 90's as efforts were undertaken to fight off theory of the Darwinian evolution (Davis and Kenyon 1993, 99-100). The main objection advanced by the ID relies precisely upon the dichotomy explained above: if the natural selection responsible for the increase of complexity in the Universe rests on chance, it is unable to bring forth entities as complex as the living organisms. An American theologian, John. F. Haught, who testified as an expert in theology at the famous trial held in the USA in 2005 against the introduction of the ID doctrine into the high school biology curriculum, defines this doctrine as "a set of ideas, as well as a vocal cultural movement, that seeks to curb the influence of Darwinism by insisting that science must invoke a non-natural 'intelligent cause' for such seemingly improbable phenomena as speciation and cellular complexity" (Haught 2008, 193).

The precise arguments in favor of the ID were proposed by two of its most vocal advocates: a biochemist Michael Behe (1996) and a mathematician William Dembski (1995). Behe has coined out the concept of the irreducible complexity as he has argued that the functions of certain complex biological 
structures could not have been developed trough the gradual increase of complexity. In regards to the origin of systems such as the biochemical machinery of vision he asserts the following: "They were designed not by the laws of nature, not by chance and necessity; rather they were planned. The designer knew what the systems would look like when they were completed then took steps to bring the systems about" (Behe 1996, 193). In the effort to explain how one might know that a given system has originated through design, Behe continues: "design is evident when a number of separate, interacting components are ordered in such a way as to accomplish a function beyond the individual components. The greater the specificity of the interacting components required to produce the function, the greater is our confidence in the conclusion of design" (Behe 1996, 193).

The intriguing link between specificity and design comes more visibly to the fore in the ID conceptualized by Dembski as the specified complexity. This is a convoluted formal argument carried out within the theory of information. In a nutshell, Dembski maintains that specified complexity appears in a given system when the system contains a great amount of independently specified information and is complex, that is, it exhibits a low probability of being formed. He illustrates these ideas with the following example: "A single letter of the alphabet is specified without being complex. A long sentence of random letters is complex without being specified. A Shakespearean sonnet is both complex and specified" (Dembski 1999, 47). Since Dembski expressly associates the process of specification with the activity of the designer, the process may be considered as reflecting the intuitive meaning of the intentional setting aside or singling out contained in the term de-sign discussed above. Yet such singling out by itself is not of any significance unless it operates on a large population of individuals thereby making the selection truly unique and original. Regardless of how persuasively Behe's and Dembski's arguments may sound, they do not provide any explanation on how to make a transition from the objective features of the design such as specificity and complexity to the subjective mental states of an intelligent designer. This is exactly where the tools of the cognitive science of religion enter in. 


\section{Intentionality and design}

The main premise for the application of the tools of the cognitive science of religion to the analysis of the ID doctrine is to establish why the human mind intuitively posits a conscious intentional agency as the the cause of the ordering of the Universe. The particular suitability of the tools of the cognitive science of religion to assess the ID doctrine consists in two factors. Firstly, these tools rely on a extremely general conception on who a god might be with no reference to any religious traditions. Barrett states that "gods, here, will refer to: (1) counterintuitive intentional agents, (2) that a group of people reflectively believe exists, (3) that have a type of existence or action (past, present, or future) that can, in principle, be detected by people, (4) and whose existence motivates some difference in human behavior as a consequence" (Barrett 2011,97). The counterintuitivity which takes up the role of supernaturality in this case implies that the tools of the cognitive science of religion easily apply in situations where the causes of ordering do not have to be of divine nature at all. Secondly, the cognitive science of religion rests on the assumption that religiosity thus conceived is an evolutionary byproduct (Boyer 2003). Accordingly, religiosity did not emerge as a result of a specific evolutionary adaptation but arose due to the operation of the ordinary natural cognitive powers of the human mind.

The first important point in the cognitive explanation of the origin of design is that the human mind exhibits a strong conceptual bias, namely, content - specific cognition, that manifests itself through an array of intuitive expectations on what the world is like and what course of the natural phenomena is to be foreseen. These expectations sum up to what is termed as the folk ontology. Pascal Boyer has pointed out that the religious beliefs where gods are conceptualized as intentional agents arise largely based on intuitive (non-reflective) concepts to facilitate the efficacy of these beliefs in the real-time operation (e.g. Boyer 2001). Barret has put forward the thesis that the quickly spreading religious concepts need to be minimally counterintuitive, that is, to violate the folk ontology only to a certain small degree (Barett and Nyhoff 2001). Additionally, these concepts must exhibit 
substantial inferential potential to form reflective beliefs so that sense can be made out of what is being observed and experienced in reality. It turns out that these are the minimally counterintuitive intentional agents equipped with mental states which qualify as the chief meaning making tools.

What are the reasons for this particular applicability of the concept of an intentional agent to make sense out of reality? The evolutionary explanations of this state of affairs rely on the two basic cognitive mechanisms called the hyperactive agency detection device (HADD) and the theory of mind (ToM) otherwise called the folk psychology. The HADD was first suggested by Stephen Guthrie and its primary function is to purposely over-interpret the perception of a self-perpelled motion as resulting from the action of an intentional agent equipped with mental states (Guthrie 1993; Barrett $2000,31)$. Since such a motion has no visible mechanical cause, it violates the expectation of physicality whereby it triggers the HADD so that the attack of a predator can be avoided and the reproductive success secured. The theory of mind supplements the workings of the HADD by supplying the array of possible mental processes and motivations that might have led to the behavior perceived (Barrett 2011, 74-77).

What truly counts as fundamental from the point of view of this study, however, is the HADD reveals sensitivity not only to the actual motions of a supposedly minded agent but to the traces of its activity as well (Barrett 2004, 36-39). The traces may include easily recognizable objects such as deer trails and bird nests as well as any other manifestations of ordering. If the encountered pattern does not correspond to any familiar mechanical or biological cause, the human mind will likely place an intentional agency as its cause because it has a natural bias towards explaining the perception of ordering in the teleological terms rather than to stipulate the activity of natural causes. This phenomenon has been extensively studied by an American psychologist, Deborah Kelemen (1999). The studies performed on young children demonstrated a marked preference in explaining a given natural regularity by answering the question "what for?”. Consequently, a design or a regularity encountered in nature can be easily clarified as the activity of an intelligent designer and - ultimately - of a creator (2004). 
Further justification of why the human mind intuitively associates orderings observed in nature with a purposeful action of an intentional agent comes from an argument based on probabilities. Some indications in this regard have been made by De Cruz and De Smedt but they call for further substantiation (De Cruz and De Smedt 2015, 72-76). What follows is a proposal of such as substantiation conjectured by the author of this study. The conditions under which local ordering in the Universe may take place, are given by the laws of thermodynamics which involve entropy as the formal measure of disorder (Penrose 1991, 309-317). These laws stipulate that the local ordering reflected in the local decrease of entropy must be accompanied by the local decrease of the internal energy. The energy of a system can be lowered through work that is performed on it (e.g., Atkins and de Paula 2014, 134-146). This fact agrees with the intuitive experience of having to invest a considerable and purposeful effort into achieving results that require organization of things into coherent unities (e.g., building a house). Similarly, the disintegration into chaos and formlessness occurs spontaneously in nature and its prevention always demands external intervention. This observation suggests that there may exist a link between the process of ordering and the activity of a personal intentional agency, that is a designer.

This link becomes evident as one considers Boltzmann's definition of entropy given by the famous formula $S=k \ln \Omega$, where $k$ is the thermodynamic constant and $\Omega$ is the number of equivalent microstates available to a system in a certain macrostate. The complexity of the system in Dembski's terms indicates that there is a large number of possible configurations - microstates available to this system whereby the probability of picking out a single one is low. Such a process of selection will result in a significant decrease of entropy as compared to the situation in which the complexity was small meaning that much greater force will need to be exerted in the same time period to achieve selection in a complex system. And now comes the key cognitive argument. According to Leslie, the subjective mental representation contains three distinct levels with the representation of a mechanical force being the most basic one that supplies information to the two higher ones 
(Leslie 1999, 137). Consequently, as Sørensen states, "representation of force is an implicit part in both understanding entities in the world as agents with intentions and in being an agent oneself when acting with specific goals in mind based on beliefs" (Sørensen 2005, 173). In conjunction with the laws of thermodynamics, this statement yields a possible explanation of why the perception of order may intuitively invoke an intentional agency as its primary cause and why such an agency produces events of low probability. Despite of its conjectural character calling for a more in-depth empirical study, it seems rational to expect that the capacity of producing design qualifies as another constituent of the folk ontology, that is, the content specific expectation of what it means to be human.

\section{Conquering counterintuitivity}

There is no doubt that the new scientific discoveries slowly but constantly shift the threshold of what qualifies as counter-intuitive. The possibility of overcoming the cognitive biases through the growth of the scientific knowledge and its subsequent cultural dissemination has been convincingly argued by De Cruz and De Smedt (2012). For instance, the introduction of one of the most fruitful conceptual tools of the contemporary physics, namely, that of a field, clearly does away with the intuitive belief that motion occurs through contact with a visible cause. Since fields are invisible carriers of forces spreading over the entire space, their effects occur as having no visible mover. More importantly, as revealed by the theory of the dissipative systems, ordering into very complex low-probability structures such as living organisms does not have to mean design because it can be brought forth by the workings of the natural laws. To put things in short, life is a dissipative structure (Heller and Życiński 1990, 104-110). According to this theory order can naturally emerge out of chaos so that no intervention of an intelligent designer is necessary in this process (Prigogine and Stengers 1990). The emergence of ordering in the Universe involves two strategies: (1) the necessity of the laws of nature combined with (2) chance as the random character of fluctuations of the environment. Since these fluctuations fall 
under rigorous mathematical treatment within the probability theory, the evolutionary origin of live in the Universe can be easily subsumed within the scientific rationality of a mathematical character (e.g. Heller 2012, 273-316). Consequently, chance no longer contradicts order but becomes its seminal constituent. This suggests that what for the scientifically illiterate generations immediately led to the acknowledgement of the workings of an intelligent designer no longer has to have this effect for those that are scientifically informed.

Moreover, the studies of the evolutionary processes of bringing forth this growth reveal that the characteristics of these processes does not coincide with the idea of a design resulting from the purposeful activity of a designer. This is particularly evident in the specificity of the natural selection that brings forth novelty not by means of the optimization of a new project but by means of slow modifications of the existing structures. In short, the novelty resulting from the workings of the natural selection is imperfect and flawed (Ayala 2007). For instance, this imperfection appears in the structure of the human brain that could have been designed as a much more efficient and structurally organized device (Korzeniewski 2005, 34-36). Interestingly enough, it turns out that yet in the $19^{\text {th }}$ century the famous advocate of the ID, William Payley, was quite aware of the imperfections of nature but in light of his overwhelming conviction on the purposeful authorship of the Universe he disregarded them on the premise that their impact was minimal (Payley [no date], 46).

In order to gain more focus in addressing this problem, Grygiel has suggested the concepts of the vincible and invincible counterintuitivity to reflect the dynamic nature of the scientific knowledge in its impact on the formation of a religious belief (Grygiel 2017). In particular, these concepts allow for the articulation a purely hypothetical situation in which counterintuitivity would eventually become entirely vincible upon the formulation of a scientific theory of everything capable of grasping the ultimate meaning of reality (e.g. Hawking and Mlodinov 2010). There is a common agreement, however, that such expectations amount to no more than sheer illusion (Heller 2006). This agreement builds on a practical and 
a theoretical premise. The practical premise was clearly stated by Albert Einstein who was deeply convinced that science unveils only a very small part of the vastness and complexity of the physical reality while most of it will always remain a profound mystery (Einstein 1931). To put things in short, nature has sufficient amount of novelties in stock to generate counterintuitivity for many generations of researchers to come. It is not surprising that Richard Swinburne has revamped the argument from design by claiming that the abstract laws of physics call for an intentional agency to explain their origin (Swinburne 1992).

The theoretical premise was clarified by Michael Heller who pointed to three irremovable gaps in knowledge that cannot be patched up with the scientific inquiry: the ontological, the epistemological and the axiological (Heller 2003). In case of the ontological gap one asks the Leibnizian question of why there exists something rather than nothing while following Einstein the epistemological gap prompts the question of why the Universe is rational, namely, why its laws assume their particular form. Since the pertinent answers fall outside the competence of science, the problem of the ultimate origin of the structuring of the Universe will never be scientifically resolved although it may shift to a very abstract level as evidenced by the highly advanced formalisms of the contemporary physical theories.

Inasmuch as the development of science is an objective process of departing from intuitions proper to the folk ontology, what truly counts for the formation of beliefs in the causal activity of intentional agencies is how the human mind responds to this development. It turns out that this response reveals two constituents. They were pointed out to by Barrett as he commented on the very process of the human mind being confronted with the outcomes of the theory of evolution: "we do not simply outgrow the tendency to see the purpose in the world but have to learn to override it" (Barrett 2011, 71). He rests this statement on extensive empirical research revealing that the folk ontology intuitions remain operative even in the conditions of the high level of scientific literacy. Consequently, these intuitions remain permanently invincible whereby the efficacy of beliefs useful in making sense out of routine events in the real time thinking is 
assured. What strikes as remarkable at this point is how well human mind is actually sealed off from the possibility of conquering all counterintuitivity: should the intuitive conceptual biases be ever overcome and should the folk ontology ever catch up with the actual state of the art in science, it is unlikely that nature itself will ever run out of surprises. And even if it finally did, the irremovable gaps will ultimately enter in and terminate all scientific inquiry.

The specificity of the mechanism of the natural selection that has been addressed at the beginning of this article points to another aspect of the invincibility of the inference of the intelligent designer's authorship of the ordering in the Universe. As it has been already explained, this mechanism executes a short sighted ad hoc strategy of imperfect adjustments to the existing structures to secure their proper adaptation to the environment's fluctuations. Since ordering does not seem to be manifest to perception in such an instance, the HADD should not fire and the activity of an intentional agent should not be detected. On the other hand, however, the detection of imperfections of the evolutionary outcomes does rely on the knowledge of rather advanced biology unavailable at the times when William Payley formulated his famous claims. Therefore, it seems justified to expect that these imperfections will not significantly obstruct the activity of the scientifically uninformed intuitions especially that the theory of dissipative systems based on the deterministic chaos yields rational explanation of their origin.

\section{In connection with religion}

Although the contemporary ID doctrine does not reveal an explicitly religious agenda, it is hard to disentangle this doctrine from its theological significance. After all, the representation of God the Creator as an intelligent designer entered the theological thought yet in the Middle Ages through the formulation of the teleological argument for the existence of God. Later on, for instance, the explanation of the complexity of living organisms given in the $19^{\text {th }}$ century by William Payley directly involved God as the principal 
author of the ordering of the Universe (Payley [no date]). It seems quite also obvious that many of the ID supporters including Behe and Dembski aimed at creating a new intellectual framework in which the prevalent scientistic attitude could be overcome and the mind of a contemporary scientifically oriented believer reopened for the perception of the supernatural. Consequently, the appraisal of the ID doctrine with the tools of the cognitive science of religion will not be complete unless the impact of the presented outcomes on the formation of the religious belief is at least briefly addressed.

Barrett has drawn up the following cognitive distinction between natural religion and theology: "there is a difference between what people tend to believe in an automatic, day-to-day sort of way, and what they believe when they stop to reflect and systematically figure out what they do and do not believe” (Barrett 2011, 139). This means that the human mind makes use of two incompatible representations of the divine: the intuitive and the theological. Since the intuitive representation is inferentially rich and its activation occurs quickly and unconsciously, it secures that the thought processes with its use guarantee immediate inferential power thereby securing the execution of religiosity in the real-time mode. The theological representation on the other hand is abstract with its activation occurring slowly and consciously in a reflective mode of religious thinking. As Barrett frequently stresses, it demands an elaborate institutional scaffolding in the form of the educational institutions to provide proper instruction (Barrett 2011, 105-106).

As applied to the ID doctrine, Barrett's distinction of religious beliefs into natural religion and theology clearly supports the invulnerability of the intuitive belief in the purposefulness of ordering in the Universe to its natural explanation by means of the evolutionary scenarios. In light of this it seems rational to propose that the religiously interpreted ID doctrine can be reasonably justified only in the mode of the natural religion as it serves to sustain the belief in God as the creator of the Universe. There is no doubt that this belief is central to any religion that attributes the origin and the existence of the Universe to the causal power of the pertinent deity. Moreover, the intuitive character of the belief in the divine design of the 
ordering in the Universe makes this belief permanently accessible to believers in real-time thinking. As a result, religiosity can be continuously exercised without the need to resort to elaborate reasonings to substantiate its claims.

\section{Concluding remarks}

The analysis of the doctrine of the Intelligent Design with the tools of the cognitive science of religion has demonstrated that the human mind exhibits a marked preference towards the intuitive (non-reflective) acceptance of an intentional agency, that is a designer, as the author of the ordering of the Universe. What is most striking, however, is that this belief seems to reveal an unusual immunity to the development of science despite of that science gradually invalidates the ID's central claims by showing that what is intuitively attributed to the activity of a designer turns out to be the result of the workings of the laws of nature. Such state of affairs gives a clear explanation of the persistence of the ID doctrine even in the scientifically literate circles. Shortly speaking, intuitions are extremely hard to be dispensed of.

An important cognitive factor which discredits the ID doctrine is the nature of the HADD itself. Since this cognitive mechanism relies on the error management strategy, it yields no insight into the epistemic value of this belief. In short, this not a truth tracking process and it is likely to generate false positives. It is additionally confirmed by the fact that the HADD was proposed on the basis of a specially constructed ancestral environment in which its activity had been adaptively advantageous. It remains beyond doubt that contemporary humans who are scientifically literate do not populate such environments. De Cruz and De Smedt confirm this difficulty when they state that "one cannot draw straightforward conclusions from evolutionary origins to epistemic justifications" (De Cruz and De Smedt 2012, 420). These considerations seem to lead to an inescapable conclusion that the ID doctrine is entirely unscientific for it fools its supporters to mythology.

Such drastic claim can be somewhat alleviated as one takes into account the thermodynamic argument of why human mind posits a designer as it perceives ordered structures. Contrary to the HADD, the mechanism involved 
relies on the second law of thermodynamics which is a well established law of nature whereby the corresponding mental representations may refract some truth on what the world really is. As is has been already indicated, an intelligent designer may be a part of what constitutes the folk psychology. Consequently, the concept of the intelligent designer can be applied to formulate positive theological statements concerning the nature of the supernatural reality. Following the precepts of the negative theology, however, such predication occurs metaphorically only due the radical disproportion between the perfection and infinity of God and the finiteness of the human conceptual means that are at man's disposal (Aquinas 1975, 141-145). The representation of God as the Creator in the form of the intelligent designer can serve only as the metaphor of God's creative power to sustain the intuitive belief and cannot be used to formulate any literal theological statements on the nature of the divine act of creation.

\section{References}

Aristotle. 1941. The Basic Works. Edited by Richard McKeon. New York: Random House.

Aquinas, Thomas. 1975. Summa Contra Gentiles I. Translated by Anton C. Pegis. Notre Dame-London: University of Notre Dame Press.

Atkins, Peter and Julio De Paula. 2014. Physical Chemistry. 10th Edition. Oxford: Oxford University Press.

Ayala, Francesco J. 2007. "Darwin's greatest discovery: Design without designer." Proceedings of the National Academy of Sciences. 104: 8567- 8573.

Ayala, Francesco J. 2009. Dar Darwina dla nauki i religii. Warszawa: Wydawnictwo Uniwersytetu Warszawskiego.

Barrett, Justin L. 2000. "Exploring the Natural Foundations of Religion." Trends in Cognitive Sciences 4(1): 29-34.

Barrett, Justin L. 2004. Why Would Anyone Believe in God?. Lanham MD: AltaMira Press. Barrett, Justin L. 2011. Cognitive Science, Religion and Theology: From Human Minds to Divine Minds. Conshohocken: Templeton Press.

Barrett, Justin L. and Melanie A. Nyhof. 2001. "Spreading the Non-natural Concepts: The Role of Intuitive Conceptual Structures in Memory and Transmission of Cultural Materials." Journal of Cognition and Culture 1: 69-100. 
Behe, Michael. 1996. Darwin's Black Box: The Biochemical Challenge to Evolution. New York: The Free Press.

Bering, Jesse M. 2011. The Belief Instinct: The Psychology of Souls, Destiny and the Meaning of Life. New York: W.W. Norton \& Company.

Boyer, Pascal. 2003. „Religious Thought and Behavior as By-products of Brain Function.” Trends in Cognitive Science 7(3): 119-124.

Boyer, Pascal. 2001. Religion Explained: The Evolutionary Origins of Religious Thought. New York: Basic Books.

Chaberek, Michał. 2014. Stworzenie czy ewolucja? Dylematy katolika. Warszawa: Fronda.

Davis, Percival and Dean H. Kenyon. 1993. Of Pandas and People: The Central Question of Biological Origins. Dallas: Haughton.

De Cruz, Helen and Johan De Smedt. 2015. A Natural History of Natural Theology. Cambridge MA: The MIT Press.

De Cruz, Helen and Johan De Smedt. 2012. "Evolved cognitive biases and the epistemic status of scientific beliefs.” Philosophical Studies 157: 411-429.

Dembski, William A. 1995. The Design Inference: Eliminating Chance Through Small Probabilities. Cambridge: Cambridge University Press.

Dembski, William A. 1999. Intelligent Design: The Bridge Between Science and Theology. Downers Grove, Illinois: InterVarsity Press.

Einstein, Albert. 1931. “The World as I see It.” Forum and Century” 84: 193-194.

Giertych, Maciej. 2016. Ewolucja, dewolucja, nauka. Warszawa: Wydawnictwo Giertych. Grygiel, Wojciech P. 2017. "Science and human religiosity from the perspective of the cognitive science of religion.” Analect Cracoviensia 49: 177-194.

Guthrie, Stewart A. 1003. Faces in the Clouds: A New Theory of Religion. New York: Oxford University Press.

Haught, John F. 2008. God After Darwin: A Theology of Evolution. Boulder CO: Westview Press.

Hawking, Stephen W. and Leonard Mlodinov. 2010. The Grand Design: New Answers to the Ultimate Questions of Life. London - Toronto - Sydney - Auckland - Johannesburg: Batnam Press,

Heller, Michał. 2003. “Chaos, Probability and the Compressibility of the World.” In Creative Tension: Essays on Science and Religion, Michał Heller, 127-143. Randor PA: Templeton Foundation Press.

Heller, Michał. 2006. “Teorie wszystkiego.” In Filozofia i wszechświat, Michał Heller, 237 - 255. Kraków: Universitas.

Heller, Michał. 2012. Filozofia przypadku. Kraków: Copernicus Center Press.

Heller, Michał and Józef Życiński. 1990. Dylematy ewolucji. Kraków: Polskie Towarzystwo Teologiczne. 
Jodkowski, Kazimierz. 2007. “Kłopoty teistycznego ewolucjonizmu.” In Kontrowersje wokół początków człowieka. edited by Grzegorz Bugajak, and Jacek Tomczyk, 209-224. Katowice: Księgarnia św. Jacka.

Keane, George J. 1999. Creation Rediscovered: Evolution and The Importance of the Origins Debate. Rockford, Illinois: TAN Books and Publishers.

Kelemen, Deborah. 1999. "Why Are Rocks Pointy? Children's Preference for Teleological Explanation of the Natural World.” Developmental Psychology 35(6): 1440-1452.

Kelemen, Deborah. 2004. "Are children "intuitive theists”? Reasoning about purpose and design in nature." Psychological Science 15(5): 295-301.

Korzeniewski, Bernard. 2005. Od neuronu do (samo)świadomości. Prószyński i S-ka.

Leslie, Alan M. 1999. “A Theory of Agency.” In Causal Cognition: A Multidisciplinary Debate, edited by Dan Sperber, David Premack, and Ann J. Premack, 121-149. Oxford: Clarendon.

Payley, William. [no date]. Natural Theology. New York: American Tract Society.

Penrose, Roger. 1991. The Emperor's New Mind. New York: Penguine Books.

Prigogine, Ilya and Isabelle Stengers. 1990. Z chaosu ku porządkowi. Warszawa: Państwowy Instytut Wydawniczy.

Sørensen, Jesper. 2005. “Charisma, Tradition and Ritual.” In Mind and Religion: Psychological and Cognitive Foundations of Religiosity, edited by Harvey Whitehouse, and Robert N. McCauley, 167-186. Walnut Creek CA: AltaMira Press.

Swinburne, Richard. 1992. “The Argument from Design.” In Readings in the Philosophy of Religion: An Analytic Approach, edited by Baruch A. Brody, 189-201. Englewood Cliffs NJ: Prentice Hall. 